\title{
O FOMENTO À CULTURA COMO VETOR DE BEM-ESTAR SOCIAL: OS INCENTIVOS DA LEI ROUANET
}

\author{
THE PROMOTION OF CULTURE AS A VECTOR OF SOCIAL WELL- \\ BEING: THE INCENTIVES OF THE ROUANET LAW
}

\author{
Gina Vidal Marcílio Pompeu ${ }^{\mathrm{I}}$ (D) \\ Paulo Sergio Freire Nogueira ${ }^{\mathrm{II}}$ (i)
}

\footnotetext{
${ }^{\mathrm{I}}$ Universidade de Fortaleza, Fortaleza, CE, Brasil. Doutora em Direito. E-mail: ginapompeu@unifor.br

II Universidade de Fortaleza, Fortaleza, CE, Brasil. Mestre em Direito. E-mail: paulosergiofreire@yahoo.com.br
}

Resumo: Por meio do artigo que ora se apresenta, tem-se por escopo analisar a lei no 8.313/1991, intitulada "Lei de Incentivo à Cultura", e conhecida como "Lei Rouanet". Cumpre lembrar que essa lei teve como fundamento as premissas do Pacto Internacional dos Direitos Econômicos, Sociais e Culturais (PIDESC), aprovado em 1966 pela Organização das Nações Unidas (ONU), e ratificado pelo Brasil em 1992. Nesse viés, a Lei Rouanet solidifica os direitos culturais e, por meio da garantia do dever do Estado, oportuniza o acesso à Cultura. Nesse diapasão, os incentivos fiscais existentes na lei são investigados, sobretudo, aqueles na modalidade do mecenato. A metodologia utilizada consiste na averiguação de fontes bibliográficas, doutrinárias, legislativas e documentais. A pesquisa tem o escopo de observar se as instituiçôes podem colaborar para a construção do Estado Social, sem a intervenção direta estatal. São examinados os gastos tributários no Brasil entre os anos de 2009 a 2017, com destaque na Cultura. Busca-se evidenciar a importância do setor como vetor de crescimento econômico e desenvolvimento humano.

Palavras-chave: PIDESC. Constituição. Estado Social. Fomento Cultural. Renúncia Fiscal.

Abstract: The purpose of this article is to analyze Law No. 8,313 / 1991, entitled "Culture Incentive Law", known as the "Rouanet Law". It should be remembered that this law was based on the premises of the International Covenant on Economic, Social and Cultural Rights (ICESCR), approved in 1966 by the United Nations (UN), and ratified by Brazil in 1992. In this regard, the Rouanet Law solidifies cultural rights and, through the guarantee of the duty of the State, gives access to Culture. In this context, the tax incentives in the law are investigated, especially those in the modality of patronage. The methodology used is the investigation of bibliographic, doctrinal, legislative, and documentary sources. The research has the scope to observe if the institutions can collaborate for the construction of the Social State, without the direct intervention state. Tax expenditures in Brazil

Recebido em: 22.08.2019

Aceito em: 21.07.2020 
are examined between 2009 and 2017, with emphasis on Culture. It seeks to highlight the importance of the sector as a vector of economic growth and human development.

Keywords: ICESCR. Constitution. Social State. Cultural Promotion. Tax Waiver.

\section{Introduçáo}

Por meio do presente estudo, almeja-se avaliar os incentivos oportunizados pela Rouanet, Lei no 8.313, de 23 de dezembro de 1991, analisar os mecanismos de fomento, sobretudo o mecenato, e de como essas ferramentas contribuem para efetivar o Estado de bem-estar social no que concerne à cultura, por meio do fortalecimento das instituiçôes, sem a intervenção direta estatal.

A Lei $\mathrm{n}^{\circ}$ 8.313/1991 tem origem nas premissas determinantes do Pacto Internacional sobre os Direitos Econômicos, Sociais e Culturais (PIDESC), cuja resolução adveio da Assembleia Geral das Naçóes Unidas, ainda no ano de 1966, mas que somente foi ratificado pelo Brasil em 1992, não obstante a instituição da Rouanet ter ocorrido no ano anterior, em 1991. Além do PIDESC, a norma tem ainda como escopo os princípios integrantes da Constituição Federal de 1988, que efetivaram os direitos culturais no Brasil.

A Lei Rouanet é alvo constante de acusaçôes de permissividade com fraudes, aprovaçáo de projetos com direcionamento político e ideológico ou com projetos considerados consagrados comercialmente, cujo fomento seria, em tese, desnecessário. Cumpre, porém, questionar se tais críticas estão no bojo do senso comum ou se persiste carência de melhorias em certas áreas que impedem o seu cumprimento e dessa forma torná-la um instrumento de vetor positivo na colaboração da efetivação dos direitos culturais.

Pretende-se abordar, por intermédio de comparativos quantitativos, os recursos advindos dos gastos orçamentários (renúncia fiscal) nos últimos 9 (nove) anos - 2009 a 2017 pela União. Utiliza-se de relatórios disponibilizados pela Receita Federal do Brasil (RFB), entre as diversas áreas beneficiadas pela renúncia fiscal e demonstra-se o impacto que essas desoneraçóes ligadas à Cultura trazem para o país e onde esta se encaixa nas prioridades das políticas públicas governamentais.

No primeiro tópico, faz-se panorama sobre o PIDESC, juntamente com a Constituiçáo de 1988, no que concerne à efetivação dos direitos culturais. No segundo tópico, apresenta-se escopo da lei atualmente e de como sua sistemática favorece o fortalecimento das instituiçóes do Estado e de suas normas.

No terceiro tópico, por meio de dados quantitativos, analisam-se a renúncia fiscal destinada a Cultura e aquelas inerentes às demais áreas governamentais nos últimos 9 
anos. Observa-se ainda de que maneira a Lei Rouanet se insere nesse processo e as possíveis falhas existentes. Arremata-se, ao final, com a proposta de um círculo virtuoso formado por Estado, instituiçóes e sociedade no qual o fomento à cultura seja potencializado na promoção do Estado de bem-estar social.

\section{A influência do Pacto Internacional dos Direitos Econômicos, Sociais e Culturais sobre a Constituição Brasileira de 1988}

Ao final da Segunda Grande Guerra Mundial, a Organização das Nações Unidas (ONU) enumera, em documento intitulado de "Carta da ONU", a necessidade de proteger a dignidade humana, dado o contexto de guerra que o mundo acabara de vivenciar. Especificamente, no artigo 55 dessa Carta, é estabelecida a proteção aos direitos humanos e que para isso os Estados-partes deverão criar mecanismos que garantam as liberdades fundamentais de todos e para todos.

A partir dessa base, em 1948, nasce a "Declaração Universal dos Direitos Humanos - DUDH" ${ }^{1}$, que em seu bojo sistematiza uma rede de direitos e liberdades fundamentais que devem ser garantidos a todos os habitantes dos Estados-partes. Para Piovesan ${ }^{2}$, embora fosse medida necessária e essencial para o desenvolvimento humano, a Declaração não possuía prisma de cunho legal, ou seja, faltava à Declaração Universal dos Direitos Humanos força jurídica vinculante.

Dessa forma, a fim de assegurar as premissas de defesa dos direitos e liberdades fundamentais, a Declaração passou por processo que a tornasse vinculante para os países que a assinaram. Segundo Piovesan, essa consolidação da DUDH veio da seguinte forma:

Esse processo de "judicialização" da Declaração começou em 1949 e foi concluído apenas em 1966, com a elaboraçáo de dois tratados internacionais distintos - o Pacto Internacional dos Direitos Civis e Políticos e o Pacto Internacional dos Direitos Econômicos, Sociais e Culturais - que passaram a incorporar os direitos constantes da Declaração Universal. ${ }^{3}$

Os dois documentos visam garantir, em escala global, a dignidade humana inserida de forma definitiva no ordenamento jurídico dos Estados-partes da ONU. Os pactos foram aprovados pela Assembleia Geral das Naçóes Unidas em 1966, mas somente em 1976 é que entraram em vigor, pois foi naquele ano que ambos atingiram o número mínimo de naçóes que ratificaram os documentos. Dados da própria Nações Unidas ${ }^{4}$

1 ORGANIZAÇÃO DAS NAÇỐES UNIDAS. A Declaração Universal dos Direitos Humanos. 1948. Disponível em: https:// nacoesunidas.org/direitoshumanos/declaracao/. Acesso em: 8 nov. 2017.

2 PIOVESAN, Flávia. Direitos Humanos e o Direito Constitucional Internacional. 15. ed. São Paulo: Saraiva, 2015. p. 237.

3 PIOVESAN, Flávia. Direitos Humanos e o Direito Constitucional Internacional. 15. ed. São Paulo: Saraiva, 2015. p. 238.

4 UNITED NATIONS HUMAN RIGHTS. Ratificação do Pacto Internacional sobre Direitos Econômicos, Sociais e Culturais, janeiro 2013. 2013. Disponível em: https://www.ohchr.org/en/professionalinterest/pages/cescr.aspx. Acesso em: 2 nov. 2018. 
revelam que, em 2013, mais de 160 nações já haviam aderido, especificamente ao Pacto Internacional dos Direitos Econômicos, Sociais e Culturais (PIDESC).

Para a $\mathrm{ONU}^{5}$, a natureza jurídica dos direitos resguardados no PIDESC, embora fossem de natureza similar, não carecem de garantias iguais nas políticas de efetivação a serem implementadas pelos Estados signatários. Os direitos culturais, por exemplo, necessitariam do Estado açóes indiretas com normas postas em simetria com os direitos civis e políticos dos cidadáos, conforme consta no Informe do Alto Comissariado das Nações Unidas:

[...] el derecho a tomar parte en la vida cultural y el derecho de los autores a los beneficios materiales y morales que se deriven de sus obras, requieren que el Estado se abstenga de emprender determinadas acciones y que respete ciertas normas mínimas que se han asociado fundamentalmente con los derechos civiles y políticos. ${ }^{6}$

Entretanto, é fato que os Estados que ratificaram o tratado se veem obrigados a praticá-los sob pena de responsabilização perante a comunidade internacional. Pompeu e Figueiredo Neto $^{7}$ argumentam que essa implementação difere quando colocados sob o mesmo prisma o PIDESC e o Pacto dos Direitos Civis e Políticos, visto que o primeiro elenca responsabilidades do Estado e o segundo é direcionado aos indivíduos, ou seja, cabe aos países signatários desenvolver instituições que busquem a efetivação dos direitos previstos no PIDESC.

Para Leão ${ }^{8}$, o PIDESC, em resumo, trata de normas que envolvem: direito do trabalho sob uma premissa igualitária, direito de organização sindical, seguridade social, proteção e assistência à família, educação e direito à cultura, enfatizando que esses direitos deverão ser elencados sob as bases da liberdade, da igualdade e da não discriminação.

Os Estados-partes que ratificaram o PIDESC são monitorados por um comitê da ONU, intitulado de Comitê de Direitos Econômicos, Sociais e Culturais (CDESC), instituído por meio da Resolução 1.985/17, de 28 de maio de 1985. Segundo Leão", é o comitê que será encarregado de receber informes sobre como os Estados estão implementando o Pacto, é responsabilidade desse comitê, que é composto por 18

5 UNITED NATIONS HUMAN RIGHTS. Informe del Alto Comisionado de las Naciones Unidas para los Derechos Humanos. 2006. Disponível em: https://www.ohchr.org/SP/Pages/Home.aspx. Acesso em: 8 nov. 2018. p. 6.

6 UNITED NATIONS HUMAN RIGHTS. Informe del Alto Comisionado de las Naciones Unidas para los Derechos Humanos. 2006. Disponível em: https://www.ohchr.org/SP/Pages/Home.aspx. Acesso em: 8 nov. 2018. p. 6.

7 POMPEU, Gina Vidal Marcílio; FIGUEIREDO NETO, Manoel Valente. Artigo 6º. In: BALERA, Wagner; SILVEIRA, Vladmir Oliveira da; COUTO, Mônica Bonetii. Comentários ao Pacto Internacional dos Direito Econômicos, Sociais e Culturais. Curitiba: Clássica, 2013. p. 111-127. p. 123.

8 LEÂO, Renato Zerbini Ribeiro. O Acesso direto dos indivíduos ao Comitê de Direitos Econômicos, Sociais e Culturais da ONU. Universitas Relaçöes Internacionais, Brasilia, v. 11, n. 1, p. 28-38, jan. 2013. Disponível em: https://www.publicacoesacademicas. uniceub.br/relacoesinternacionais/article/download/2325/2068. Acesso em: 8 nov. 2018. p. 35.

9 LEÂO, Renato Zerbini Ribeiro. O Acesso direto dos indivíduos ao Comitê de Direitos Econômicos, Sociais e Culturais da ONU. Universitas Relaçôes Internacionais, Brasilia, v. 11, n. 1, p. 28-38, jan. 2013. Disponível em: https://www.publicacoesacademicas. uniceub.br/relacoesinternacionais/article/download/2325/2068. Acesso em: 8 nov. 2018. p. 36. 
profissionais especialistas, definir as carências dos Estados-partes na efetivação das premissas existentes no PIDESC.

Em 2008, um protocolo facultativo ligado ao PIDESC foi lançado em comemoração ao $60^{\circ}$ aniversário da DUDH. Segundo o Ministério Público Federal ${ }^{10}$, o protocolo é uma ferramenta necessária e complementar aos trabalhos da comissão do PIDESC. Para o MPF, é com base nesse protocolo que se terá a possibilidade de ofertar às vítimas que tiveram esses direitos violados a condição de buscar justiça, no propósito de almejar a reparação na medida do ato transgressor referente aos direitos estabelecidos no PIDESC.

Entretanto, até o momento, o Brasil não ratificou tal protocolo. Urge a necessidade de o país endossar essa iniciativa, se almeja de fato ofertar tais direitos aos seus cidadãos. Tal posição é compartilhada pelo $\mathrm{MPF}^{11}$, sob o argumento de que a possibilidade da "combinação do mecanismo de petição com o de investigação, e a possibilidade de medidas provisionais, contribuirá para formar um conjunto de jurisprudência sobre estes direitos, ajudando, desta maneira, os Estados a assegurarem sua implementaçáo”.

No que diz respeito à cultura, o PIDESC traz, no artigo 15, as iniciativas que os Estados-partes devem adotar como parâmetro. Formalmente, o texto almeja para os cidadãos a garantia da liberdade individual cultural, com atenção para as seguintes determinantes:

Artigo 15: $§ 1$. Os Estados-partes no presente Pacto reconhecem a cada indivíduo o direito de: 1. Participar da vida cultural; 2. Desfrutar o progresso científico e suas aplicaçôes 3. Beneficiar-se da proteção dos interesses morais e materiais decorrentes de toda a produção científica, literária ou artística de que seja autor. $\$ 2$. As medidas que os Estados-partes no presente Pacto deverão adotar com a finalidade de assegurar o pleno exercício desse direito incluirão aquelas necessárias à conservação, ao desenvolvimento e à difusão da ciência e da cultura. ${ }^{12}$

Reitera-se que o PIDESC se trata de pacto de implantação progressiva, ou seja, os Estados-partes deverão estabelecer parâmetros para que tais direitos sejam garantidos ano após ano. Entretanto, essa progressividade garante ao PIDESC a impossibilidade dos Estados-partes de retrocederem no que foi avançado sob pena de penalidade por parte do Comitê gestor do pacto. Piovesan ${ }^{13}$ argumenta que, em caso de retrocesso no que já foi implantado, o Estado terá o ônus de provar à comunidade internacional que possui medidas que garantam o contrário, ou seja, deverá demonstrar que tais direitos não estão sendo reduzidos, e sim ampliados.

10 BRASIL. Protocolo facultativo ao PIDESC: uma ferramenta para exigir os DESC. 2009. Disponível em: pfdc.pgr.mpf.mp.br/ atuacao-e-conteudos-de-apoio/publicacoes/direitos-humanos/protocolo. Acesso em: 8 nov. 2018. p. 7.

11 BRASIL. Protocolo facultativo ao PIDESC: uma ferramenta para exigir os DESC. 2009. Disponível em: pfdc.pgr.mpf.mp.br/ atuacao-e-conteudos-de-apoio/publicacoes/direitos-humanos/protocolo. Acesso em: 8 nov. 2018p. 7.

12 UNITED NATIONS HUMAN RIGHTS. Ratificaçāo do Pacto Internacional sobre Direitos Econômicos, Sociais e Culturais, janeiro 2013. 2013. Disponível em: https://www.ohchr.org/en/professionalinterest/pages/cescr.aspx. Acesso em: 2 nov. 2018.

13 PIOVESAN, Flávia. Direitos Humanos e o Direito Constitucional Internacional. 15. ed. São Paulo: Saraiva, 2015. p. 257. 
A garantia dos direitos econômicos, sociais e culturais existente no PIDESC é um passo valioso na busca por um desenvolvimento humano. Segundo Sen ${ }^{14}$, tais direitos traduzem-se na possibilidade de melhorar as capacidades humanas e assim aproximar-se de um ideário de bem-estar social no que diz respeito às respectivas áreas.

Ao aprofundar essa perspectiva, Nussbaum ${ }^{15}$ considera que a defesa das artes e de suas áreas correlatas, ou seja, defesa da cultura, de forma geral, representa importante meio de combater as desigualdades existentes no mundo e que, ao incentivar isso, os Estados estarão capacitando suas sociedades com consciência moral suficiente para impedir o "nacionalismo agressivo" e determinadas ideologias.

No Brasil, embora tenha ratificado o acordo somente na década 90, as premissas do PIDESC, em consonância com a DUDH, têm na Constituição Federal (CF) de 1988 marco importante, sobretudo na efetivação dos direitos culturais, com a perspectiva de liberdade e participação social, cuja previsibilidade consta no artigo 15 do PIDESC, já citado.

A Constituição elenca alterações com relação aos textos anteriores, dentre as quais mudanças justamente no âmbito cultural, com a inserção de um campo exclusivo para os temas ligados à cultura, algo náo visto nos demais textos constitucionais brasileiros anteriores. Houve uma solidificação dos direitos culturais, já garantidos no PIDESC, ainda nas décadas de 60/70, e com isso passou o Estado brasileiro a ter responsabilidades diretas e indiretas de fomentar a cadeia cultural no país.

Com base na DUDH, Cunha Filho ${ }^{16}$ enumera que, a partir de 1988, os direitos culturais seriam definidos como aqueles ligados às artes, à memória coletiva e ao fluxo de saberes, o que possibilita, segundo ele, que as pessoas se localizem temporalmente e socialmente, com o objetivo de favorecer a dignidade e o desenvolvimento humano. Para Rojas $^{17}$, os direitos culturais garantem aos diversos grupos que compóem determinada sociedade o poder de manifestar-se livremente com base em sua herança cultural.

Com isso, resta evidenciado o caráter subjetivo desses direitos e a necessidade de estímulo por parte do Estado brasileiro. Costa e Telles ${ }^{18}$, ao corroborar com esse pensamento, argumentam que, por ser um direito subjetivo, os direitos culturais, além de exigir a intervenção positiva do Estado, têm como garantia a protetiva contra quaisquer violaçóes por parte do poder público, que caracterizem retrocesso.

14 SEN, Amartya. A ideia de justiça. Rio de Janeiro: Companhia Digital, 2011. p. 308.

15 NUSSBAUM, Martha C. Sem fins lucrativos: Por que a democracia precisa das humanidades: WMF Martins Fontes, 2015. p. 24.

16 CUNHA FILHO, Francisco Humberto. A mutação do Locus Jurídico do Tombamento: do direito administrativo para os direitos culturais. Publicaçôes Escola da Agu, Brasília, v. 9, n. 3, p. 100-117, jan. 2017. Disponível em: http://seer.agu.gov.br/index.php/ EAGU/issue/view/124. Acesso em: 5 nov. 2018. p. 106.

17 ROJAS, Lucero Ibarra. Políticas Culturales y Derechos Culturales através de los Diablos de Ocumicho. Direito, Estado e Sociedade, Rio de Janeiro, n. 48, p. 196-223, jan. 2016. p. 198.

18 COSTA, Rodrigo Viera; TELLES, Mário Ferreira de Pragmácio. Cultura e Direitos culturais. Rio de Janeiro: Lumen Juris, 2017. p. 47. 
O texto constitucional de $1988^{19}$, nos artigos 215 e 216, resumidamente, garante, de forma tácita, "pleno exercício dos direitos culturais" e ainda proteção, por parte do Estado, das "manifestaçóes das culturas populares, indígenas e afro-brasileiras" e incluem ainda como patrimônio, antes apenas histórico-artístico, e agora patrimônio cultural brasileiro, "os bens de natureza material e imaterial". No artigo 216, no parágrafo $3^{\circ}$, a CF/88 determina, inclusive, que a "lei estabelecerá incentivos para a produção e o conhecimento de bens e valores culturais." 20

Além do PIDESC e da Constituição, é importante mencionar que o Brasil também é signatário do Pacto de San José da Costa Rica, que culminou com a formulação da Convenção Americana de Direitos Humanos $(\mathrm{CADH})^{21}$, onde, no artigo 26, os direitos culturais estáo garantidos como políticas institucionais de desenvolvimento progressivo, semelhante à previsibilidade existente no PIDESC. Ou seja, os direitos culturais devem ser induzidos pelo fomento, por meio do Estado e que garantam a liberdade de manifestação cultural com base em suas origens e escolhas, e que essas iniciativas devem ser progressivamente difundidas e nunca retraídas.

Não menos importante está a inserção das diretrizes estabelecidas no PIDESC, na Agenda 2030 das Nações Unidas ${ }^{22}$, que prevê 17 Objetivos de Desenvolvimento Sustentável e 169 metas que deverão ser foco dos países que compóem a ONU até o ano de 2030. O estabelecimento de normas que garantam a efetividade dos direitos culturais contribuirá para o desenvolvimento sustentável, com o fortalecimento de instituiçóes eficientes e de caráter inclusivo e responsável, de modo a atender a meta de no 16 da Agenda.

\section{$3 \mathrm{O}$ fortalecimento das instituiçóes por meio da norma de fomento à cultura}

Quando se toma como parâmetro as políticas institucionais previstas no âmbito internacional e ratificadas pelo Brasil, e diante da CF/88 e seus objetivos formais de bem-estar social e consequente desenvolvimento humano no que diz respeito à cultura, é possível afirmar ser a Lei no 8.313/91 norma garantidora de política pública de desenvolvimento de direito essencial para o almejado estado de bem-estar social.

19 BRASIL. Constituiçấo da República Federativa do Brasil de 1988. Presidência da República, Brasília, DF, 1988. Disponível em: http://www.planalto.gov.br/ccivil_03/constituicao/constituicao.htm. Acesso em: 7 nov. 2018.

20 BRASIL. Constituição da República Federativa do Brasil de 1988. Presidência da República, Brasília, DF, 1988. Disponível em: http://www.planalto.gov.br/ccivil_03/constituicao/constituicao.htm. Acesso em: 7 nov. 2018.

21 COMISSÃO INTERAMERICANA DE DIREITOS HUMANOS. Convenção Americana sobre Direitos Humanos. San José, Costa Rica, em 22 de novembro de 1969. Disponível em: https://www.cidh.oas.org/basicos/portugues/c.convencao_americana.htm. Acesso em: 8 nov. 2018.

22 ORGANIZAÇÃO DAS NAÇÓES UNIDAS. 17 objetivos para transformar nosso mundo. 2015. Disponível em: https://nacoesunidas. org/pos2015/ods16/. Acesso em: 8 nov. 2017. 
Lassale $^{23}$ já afirmara que a norma constitucional é forma jurídica basilar mais importante de um povo, e que por meio dos mandamentos previstos naquele texto serão garantidas, às sociedades, a institucionalização dos seus direitos, entre eles, os culturais. Conforme citado, a CF $/ 88^{24}$, de forma clara, no artigo $216, \$ 3^{\circ}$ afirma a necessidade de o Estado fomentar a cultura com toda sua diversidade existente.

Essa determinaçáo vai ao encontro do que rege o pactuado pelo Brasil no PIDESC, de forma que cabe ao Estado prover a cultura dentro dos parâmetros constitucionais. Bercovici aventa essa possibilidade, ao afirmar que as determinaçóes de fins de Estado são importantes, "[...] no fato de permitir, sem romper com a legalidade constitucional, avançar pela concretização de determinados objetivos." 25

Dessa forma, a Lei no 8.313/91 vem atender à necessidade do fortalecimento das instituições, que, ao cumprir sua função determinada pela Constituição, bem como atender às premissas do PIDESC, tem o potencial de canalizar, pelo menos naquele aspecto a que ela se propóe, o que Pompeu e Siqueira ${ }^{26}$ definem como "formação de um patamar mínimo civilizatório”.

Sob o prisma histórico, as origens da Lei no 8.313/91 remontam à antiga Lei no 7.505/8627, também conhecida como Lei "Sarney". Segundo Costa ${ }^{28}$, na década de 1980, o Brasil enfrentava a redemocratização política após vinte anos de Regime militar. É nesse cenário que surge a primeira lei de incentivo à cultura brasileira, a Lei n ${ }^{\circ} 7.505$, de 2 de julho de 1986. Foi a partir dessa legislação que nasceram os primeiros incentivos de projetos culturais por meio de estímulos fiscais.

Em 1990, o então Presidente Fernando Collor de Mello realizou profundas mudanças na área cultural do país. Em seu governo, houve uma radical modificação estrutural no que diz respeito à cultura no Brasil, a qual Santos resume da seguinte forma: "Assim que assumiu a Presidência da República, em março de 1990, Fernando Collor de Mello extinguiu todas as instituições e órgãos culturais." ${ }^{29}$ Paralelo à extinção em massa

23 LASSALE, Ferdinand. A Essência da Constituição. 5. ed. Rio de Janeiro: Lumen Juris, 2000. p. 8-17.

24 BRASIL. Constituiçăo da República Federativa do Brasil de 1988. Presidência da República, Brasília, DF, 1988. Disponível em: http://www.planalto.gov.br/ccivil_03/constituicao/constituicao.htm. Acesso em: 7 nov. 2018.

25 BERCOVICI, Gilberto. Política econômica e direito econômico. Pensar, Fortaleza, v. 12, n. 2, p. 363-836, jun. 2011. Disponível em: http://periodicos.unifor.br/rpen. Acesso em: 7 nov. 2018. p. 577.

26 POMPEU, Gina Vidal Marcílio; SIQUEIRA, Natercia Sampaio. Democracia Contemporânea e os critérios de justiça para o desenvolvimento socioeconômico: Direito Constitucional nas relaçóes econômicas. Rio de Janeiro: Lumen Juris, 2017. p. 165.

27 BRASIL. Lei no 7.505, de 2 de julho de 1986. Dispóe sobre benefícios fiscais na área do imposto de renda concedidos a operaçóes de caráter cultural ou artístico. Presidência da República, Brasília, DF, 1986. Disponível em: http://www.planalto.gov.br/ccivil_03/ LEIS/L7505.htm. Acesso em: 8 nov. 2018.

28 COSTA, Maíra Lopes Viana da. A lei de incentivo como politica cultural: o papel da comissão nacional de incentivo à cultura. 2013. 116 f. Dissertação (Mestrado em Bens Culturais e Projetos Sociais) - Fundação Getúlio Vargas, Rio de Janeiro, 2013. Disponível em: https://bibliotecadigital.fgv.br/dspace/bitstream/handle/10438/11293/Dissertação-Maíra LopesViana da Costa.pdf. Acesso em: 1 dez. 2017. p. 32.

29 SANTOS, Fernando Burgos Pimentel dos. Política Cultural no Brasil: histórico de retrocessos e avanços institucionais. In: ENCONTRO DA ANPAD, 33., 2009, São Paulo. Anais [...]. São Paulo: Anpad, 2009. Disponível em: http://www.anpad.org.br/ admin/pdf/APS3105.pdf. Acesso em: 2 nov. 2018. p. 11. 
dessa estrutura, foram criados novos órgãos. No entanto, tal decisão abrupta de extinção gerou descontentamento na classe artística do país, o que o fez buscar alternativas para melhorar sua imagem, dentre as quais a reformulação da Lei Sarney, que, por intermédio do então Secretário Nacional de Cultura, Sérgio Paulo Rouanet, concebeu a Lei ${ }^{\circ}$ 8.313/91 ou simplesmente Lei "Rouanet". ${ }^{30}$

A Lei $\mathrm{n}^{\circ}$ 8.313/91 em seu bojo (Art. $1^{\circ}$ ) institui o Programa Nacional de Apoio à Cultura (Pronac), cujo objetivo é fortalecer a produção, difusão e democratização do acesso à cultura. No artigo $2^{\circ}$, são apresentadas as formas de fomento à cultura que serão induzidas pelo Estado: "Art. $2^{\circ} \mathrm{O}$ Pronac será implementado através dos seguintes mecanismos: I - Fundo Nacional da Cultura (FNC); II - Fundos de Investimento Cultural e Artístico (Ficart); III - Incentivo a projetos culturais." ${ }^{31}$

A Lei Rouanet condiciona em seu texto, como forma de atingir o que determina o artigo $1^{\circ}$, diversas frentes que visam ao desenvolvimento e à maturidade do setor cultural no país, com disposiçôes de que tais projetos culturais devem conter: incentivo à formaçáo artística e cultural, fomento à produção cultural e artística, preservação e difusão do patrimônio artístico, cultural e histórico, estímulo ao conhecimento dos bens e valores culturais, além de apoio a outras atividades culturais e artísticas.

No artigo $3^{\circ}$, o legislador delimitou onde devem ocorrer tais incentivos com a finalidade de desenvolvimento do setor cultural brasileiro. Cesnik ${ }^{32}$ argumenta que a Rouanet, embora seja direcionada ao desenvolvimento da cultura brasileira, não excluiu o incentivo a projetos culturais estrangeiros que desejem apresentar-se no país.

Os dispositivos seguintes da lei irão tratar justamente da regulamentaçáo dos fundos previstos no artigo $2^{\circ}$. É possível afirmar que, formalmente, a Lei Rouanet acena para uma tentativa de dar resolutividade para que a cultura no Brasil atinja sua almejada igualdade material - um dos pilares da dignidade humana.

Cumpre ressaltar que Fukuyama ${ }^{33}$ é um entusiasta dessa possibilidade de a lei servir para seus fins de forma orgânica sem a interferência direta do poder público. Ele acredita que essa seja a chave para o sucesso de qualquer política pública e enumera lições administrativas que deveriam ser levadas de forma institucional pela máquina governamental e, embora pareça óbvio, essas liçôes ainda representam um grande desafio em muitas naçóes:

30 BRASIL. Lei $n^{\circ}$ 8.313, de 23 de dezembro de 1991. Restabelece princípios da Lei $\mathrm{n}^{\circ}$ 7.505, de 2 de julho de 1986, institui o Programa Nacional de Apoio à Cultura (Pronac) e dá outras providências. Presidência da República, Brasília, DF, 1991. Disponível em: http://www.planalto.gov.br/ccivil_03/LEIS/L8313cons.htm. Acesso em: 7 nov. 2018.

31 BRASIL. Lei $\mathrm{n}^{\circ}$ 8.313, de 23 de dezembro de 1991. Restabelece princípios da Lei $\mathrm{n}^{\circ}$ 7.505, de 2 de julho de 1986, institui o Programa Nacional de Apoio à Cultura (Pronac) e dá outras providências. Presidência da República, Brasília, DF, 1991. Disponível em: http://www.planalto.gov.br/ccivil_03/LEIS/L8313cons.htm. Acesso em: 7 nov. 2018.

32 CESNIK, Fábio de Sá. Guia do incentivo à cultura. 2. ed. Barueri: Manole, 2007. p. 20.

33 FUKUYAMA, Francis. Construção de Estados. Rio de Janeiro: Rocco, 2005. p. 23. 


\begin{abstract}
A força, neste sentido, inclui, como observado anteriormente, a capacidade de formular e executar políticas e decretar leis; de administrar com eficiência e com o mínimo de burocracia; de controlar a politicagem, a corrupção e o suborno; de manter um alto nível de transparência e responsabilidade nas instituiçóes governamentais; e, mais importante de fazer cumprir as leis. ${ }^{34}$
\end{abstract}

Entre os mecanismos de fomento à cultura existentes na Rouanet, está o Fundo Nacional de Cultura (FNC). É por meio dele que se tenta balancear a distribuição de recursos entre as diversas regióes brasileiras, visando projetos de pouca viabilidade econômica, é estimulado por recursos diretos do orçamento do Ministério da Cultura (MinC), cujas fontes são advindas de doaçôes, legados e 3\% da arrecadação bruta das loterias federais.

A Lei Rouanet prevê também os chamados Fundos de Investimento Cultural e Artístico (Ficart). Trata-se de um fundo de captação no mercado, que visa ao financiamento de atividades culturais de retorno comercial e prevê lucro para o investidor. O objetivo do Ficart é de captar recursos no mercado financeiro para investimento em projetos de alta viabilidade econômica, vislumbrando ao investidor retorno do montante investido. $\mathrm{O}$ mecanismo funciona com base em quotas de fundos em condomínio de responsabilidade das instituições financeiras, cuja tutela de fiscalização recai sobre a Comissão de Valores Mobiliários (CVM). Entretanto, esse mecanismo nunca fora implementando.

Para Gomes ${ }^{35}$, uma das razóes para o insucesso do Ficart recai sobre "a complexa questão fiscal" o que para ela "não se mostra atrativa aos investidores, não incentiva a aplicação de recursos em grandes projetos da indústria cultural e o motivo é simples: além da exação não estimular, ocorre a incerteza do retorno financeiro" argumenta. Com as dificuldades existentes nesse fundo, os projetos da chamada Indústria Cultural acabaram se acomodando na estrutura de incentivo fiscal, oferecida pela Rouanet e conhecida como mecenato, termo que significa a ação de garantir apoio às artes, ciências, literatura etc., por meio da figura do mecenas. É por meio dessa figura secular com origem no Império Romano que as artes, de uma forma geral, ganharam uma espécie de patrono.

Com isso, não é coincidência que o inciso III do artigo $2^{\circ}$ da Lei Rouanet ${ }^{36}$, intitulado de "Incentivos a projetos culturais", adquiriu essa nomenclatura, uma vez que o incentivo previsto em lei se dá por meio da iniciativa privada em troca de renúncia fiscal governamental. Para Cunha Filho ${ }^{37}$, a previsão de fomento formulada denota da

34 FUKUYAMA, Francis. Construção de Estados. Rio de Janeiro: Rocco, 2005. p. 23.

35 GOMES, Ana Paula de Oliveira. A problemática dos fundos de investimento cultural e artístico (FICART). In: ENCONTRO INTERNACIONAL DE DIREITOS CULTURAIS, 2., 2013, Fortaleza. Anais [...]. Fortaleza: OUI-IOHE, 2013. Disponível em: www.direitosculturais.com.br/download.php?id=59. Acesso em: 8 nov. 2018. p. 7.

36 BRASIL. Lei no 8.313, de 23 de dezembro de 1991. Restabelece princípios da Lei $n^{\circ} 7.505$, de 2 de julho de 1986, institui o Programa Nacional de Apoio à Cultura (Pronac) e dá outras providências. Presidência da República, Brasília, DF, 1991. Disponível em: http://www.planalto.gov.br/ccivil_03/LEIS/L8313cons.htm. Acesso em: 7 nov. 2018.

37 CUNHA FILHO, Francisco Humberto. Cultura e democracia na Constituição Federal de 1988: representação de interesses e sua aplicaçâo ao Programa Nacional de Apoio à Cultura. 2004. 234 f. Tese (Doutorado em Direito) - Faculdade de Direito do Recife, Universidade Federal de Pernambuco, Recife, 2004. Disponível em: http://www.direitosculturais.com.br/artigos_interna. 
necessidade de o Estado atentar para as situaçóes distintas dentro do cenário cultural. $\mathrm{O}$ autor destaca, ainda, exemplos de situaçóes visadas com cada tipo de fomento, tais como: manifestações distintas, posições econômicas díspares de produção, observância de riscos e pluralismo cultural.

Essa amplitude de fomentos existentes na Rouanet se traduz na necessidade de possibilitar, a um país continental como o Brasil, a canalização da norma como verdadeira reconhecedora das diversas realidades que o país tem. Afinal, o contexto cultural da cidade de Sáo Paulo náo pode ser comparado com o mesmo contexto cultural de uma pequena cidade do interior brasileiro. Tais bases democráticas desse fomento são vistas por Nussbaum ${ }^{38}$ como parte de um modelo de desenvolvimento humano que favorece a potencialização dos direitos fundamentais, pois permitem formalmente que a cultura chegue a todos.

\section{A Lei Rouanet e os aspectos da renúncia fiscal}

Mesmo com bases valorativas institucionais formalmente delineadas, a realidade material da Lei Rouanet não atende ao que ela se propõe. O FNC, por exemplo, sofre com os rearranjos orçamentários do Governo Federal, em razão de sua dependência ser de $100 \%$ em relação aos recursos diretos do Estado, tal afirmação é retirada da própria página oficial da lei, mantida pelo Governo Federal:

Justamente por ser composto majoritariamente por recursos do orçamento federal, o FNC é afetado diretamente por qualquer alteraçáo na arrecadaçáo de recursos pela União. Nos últimos anos, o FNC sofreu com sucessivas reduçôes orçamentárias. Em 2014, o Projeto de Lei Orçamentária Anual (PLOA) previa um crédito de aproximadamente $\mathrm{R} \$ 167$ milhóes, sendo que, deste montante, foram empenhados pouco mais de $\mathrm{R} \$$ 138 milhôes. Para 2015, o PLOA aprovou um orçamento de cerca R $\$ 163,7$ mi, dos quais, somente $\mathrm{R} \$ 74,4 \mathrm{mi}$ foram empenhados e $\mathrm{R} \$ 11,3$ milhóes foram efetivamente pagos. Já em 2016, a queda foi ainda maior: o próprio projeto de lei orçamentária previu dotação de R 100 milhões. ${ }^{39}$

Essa posição do Estado, em não seguir o que a lei determina, na tentativa de encobrir desarranjos orçamentários, seria um dos grandes entraves para que a lei de incentivo à cultura cumpra suas determinantes como vetor do estado de bem-estar social. Fukuyama ${ }^{40}$ acrescenta também que esses modelos de ingerência pública, como o visto no caso do FNC, impedem que as naçóes alavanquem o seu desenvolvimento, pois afetam diretamente as instituiçóes. 
A Lei Rouanet enfrenta também posicionamentos que questionam a forma e os valores movimentados na modalidade mecenato, seu fomento mais eficaz no que sempre se propôs a fazer, conforme rege a lei. Em 2017, por exemplo, dados do Ministério da Cultura, disponíveis para consulta pública na internet ${ }^{41}$, revelam que 5.456 projetos foram aprovados como aptos a captar recursos via renúncia fiscal. Isso significa que tais projetos estavam autorizados a buscar na iniciativa privada o custeio para a sua efetivação, com o poder público garantindo a renúncia via imposto de renda.

Entretanto, autorizar não significa uma captação efetiva, de modo que dos 5.456 projetos autorizados, apenas 2.871 captaram recursos. A autorizaçáo via incentivo fiscal previa o valor de $\mathrm{R} \$$ 6.122.707.354,75, mas esse patamar atingiu o valor de renúncia fiscal efetiva de $\mathrm{R} \$ 1.189 .044 .906,85$.

É dentro desse percentual, por exemplo, que a Lei Rouanet garante - via incentivo fiscal - projetos culturais contínuos. Menezes ${ }^{42}$ relata entre esses projetos: o Festival de Jazz e Blues, no Ceará; a Festa Literária de Paraty-FLIP, no Rio de Janeiro; a Bienal do Mercosul, no Rio Grande do Sul; o Festival de Teatro de Curitiba, no Paraná e o Festival Folclórico de Parintins, no Amazonas, dentre outros.

Além desses projetos, a Lei Rouanet viabiliza ainda o funcionamento de diversos centros culturais em todo o país. Conforme Menezes ${ }^{43}$, algumas instituiçôes estão "ligadas diretamente ao seu patrocinador”. Enquadra-se nesse modelo os Centros Culturais do Banco do Brasil e os Centros Culturais da Caixa Econômica Federal, por exemplo. Entretanto, há outras instituiçôes que fazem uso do financiamento da Rouanet, mas sem vinculação direta com um patrocinador específico, como o Museu Paço do Frevo, em Pernambuco, Museu de Arte do Rio de Janeiro, Museu de Arte de São Paulo (MASP), entre outras inúmeras instituições.

Existe no Brasil senso comum de que a Lei Rouanet concentra uma grande quantidade de recursos e que são destinados, por exemplo, ao mecenato. Tal afirmação, alardeada por certos setores da sociedade, é tida como um posicionamento ilusório. Mesmo encabeçando o financiamento de importantes projetos culturais, as desoneraçóes fiscais envolvendo a cultura no país não figuram nem entre as dez primeiras áreas que se utilizam desse benefício indireto. Com base em dados estatísticos da Receita Federal do Brasil, sobre a renúncia fiscal destinada à cultura, verifica-se que, embora possua previsão constitucional e compromisso do país perante a comunidade internacional, não há uma política de fortalecimento contínuo das instituições fomentadoras da área.

41 BRASIL. Ministério da Cultura. Sistema de Apoio às Leis de Incentivo à Cultura. Salic. Disponível em: http://sistemas.cultura.gov. br/comparar/salicnet/salicnet.php\#. Acesso em: 6 nov. $2018 \mathrm{~b}$.

42 MENEZES, Henilton. A Lei Rouanet: muito além dos (F)atos. São Paulo: E-galaxia, 2016. p. 162.

43 MENEZES, Henilton. A Lei Rouanet: muito além dos (F)atos. São Paulo: E-galaxia, 2016. p. 184. 
Toma-se, como exemplo, o mesmo ano corrente de 2017, no relatório intitulado "Demonstrativo dos Gastos Governamentais Indiretos de Natureza Tributária (DGT)" "44 produzido pela Receita, o qual revela que a renúncia fiscal federal destinou para a cultura uma previsão de $\mathrm{R} \$ 1.832 .436 .652$, portanto, muito próximo ao constatado nas captaçóes efetivas vistas via mecenato da Rouanet no mesmo ano. A diferença pode ser atribuída a outras atividades de incentivo, como o audiovisual, que também faz uso da modalidade de renúncia fiscal. $\mathrm{O}$ valor da previsão deixou a cultura com $0,64 \%$ de toda a renúncia fiscal federal de 2017, na $13^{\circ}$ posição entre as áreas governamentais daquele ano.

Não obstante, é importante citar que entre os anos 2009 e 2017, nas áreas governamentais que fazem uso de renúncia fiscal, a cultura só esteve na lista das dez primeiras áreas em 2010, quando fez uso de 1,52\% de toda renúncia fiscal prevista para aquele ano, que foi de $\mathrm{R} \$ 113.875 .428 .613$.

Como parâmetro comparativo, a renúncia fiscal garantida para Comércio e Serviços atingiu 30,97\% em 2010, e chegou ao valor de R \$ 35.270.718.063. Foram o Comércio e Serviços que lideraram o ranking das áreas que mais se beneficiam com as renúncias, entre os anos de 2009 e 2017, cuja titulação a Receita atribui o nome de "Gastos Tributários". Em 2017, o setor Comércio e Serviço teve previsão de renúncia fiscal da ordem de $\mathrm{R} \$ 82.789 .699 .161$, e ficou com $29,06 \%$ de todos os gastos tributários contabilizados previstos.

O entendimento que se apresenta mostra então que a Lei Rouanet encontra ressonância formal nas determinantes dos pactos internacionais firmados pelo Brasil, como também pela Constituição, na busca por um Estado de bem-estar social. Entretanto, no campo material, os ditames constitucionais reverberados por meio da lei de incentivo à cultura não possuem um indicativo claro de efetividade. Hesse atribui a essa falta de êxito na aplicação como ausência de força normativa da constituiçáo. Diz ele: "A constituição adquire força normativa na medida em que logra realizar essa pretensão de eficácia." ${ }^{45}$

O fomento a projetos culturais, seja direto ou indireto, alimenta nicho ainda quase inexplorado pelo poder público, vide suas opçôes já demonstradas de renúncia fiscal. Trata-se de enxergar o setor cultural com possibilidade de retorno, não apenas sob a ótica de bem-estar social, o que parece óbvio nesse parâmetro, mas sim sob a ótica mercantilista.

Benhamou ${ }^{46}$ explica que na França, por exemplo, os setores ligados à cultura passaram a ter reconhecimento sob o prisma econômico, pois se constatou a possibilidade de geraçáo de fluxo de renda e de emprego. A autora afirma que as famílias francesas, ainda

44 BRASIL. Receita Federal do Brasil. Demonstrativo dos Gastos Governamentais Indiretos de Natureza Tributária. Brasilia: Receita Federal, 2018c. Disponível em: http://idg.receita.fazenda.gov.br/dados/receitadata/renuncia-fiscal/previsoes-ploa/arquivos-eimagens/demon strativos-dos-gastos-tributarios-dgt. Acesso em: 5 nov. 2018.

45 HESSE, Konrad. A força normativa da Constituição. Porto Alegre: Sergio Antonio Fabris Editor, 1991. p. 19.

46 BENHAMOU, Françoise. A economia da cultura. Cotia, SP: Ateliê Editorial, 2007. p. 18-24. 
em 2001, já destinavam 4\% de seu orçamento doméstico a gastos com bens culturais. Entretanto, Benhamou ${ }^{47}$ ressalta que, mesmo naquele país europeu, o setor cultural tem fragilidade com custos elevados e ausência de reservas de produtividade, o que para ela justifica "a amplitude de subvençóes públicas."

Tais "subvenções públicas" à cultura citadas são vistas em toda a Europa, e até mesmo nos Estados Unidos, seja em menor ou maior grau. Reis ${ }^{48}$ explica que, se na França, o Estado atua no fomento à cultura de forma direta, bem como na Itália, no Reino Unido esse fomento se dará de forma indireta; já nos países escandinavos, a responsabilidade é unicamente do Governo Federal, enquanto que na Alemanha e Espanha fica a cargo de suas regiôes definirem a melhor forma de promoção.

Mesmo nos Estados Unidos, onde a iniciativa privada é a maior fomentadora de acesso à cultura, há legislaçóes e iniciativas públicas do Estado, segundo explica Reis ${ }^{49}$, que garantem a efetivação de projetos culturais sem fins comerciais, utilizando-se do fomento indireto.

No Brasil, além da falta de interesse em fortalecer os mecanismos de fomento, há ainda no aspecto governamental de aplicabilidade da lei dúvidas no que concerne ao tipo e à qualidade dos projetos culturais aprovados, sobretudo, por meio de incentivo fiscal (mecenato). Em 2017, a Lei Rouanet foi alvo de investigação por parte de Comissão Parlamentar de Inquérito (CPI) oriunda da Câmara dos Deputados. A CPI apresentou relatório que se destinou a apurar irregularidades nas concessóes de benefícios fiscais decorrentes da aplicação da lei.

O relatório ${ }^{50}$ esmiúça a legislação vigente e, entre tantas considerações, argumenta que dos três fomentos existentes na Lei, o FNC, que seria a iniciativa responsável em focar em projetos de pouca viabilidade comercial, vive um atrofiamento com sucessivos cortes devido à escassez de recursos; o Ficart nunca fora ao menos implantado e o incentivo fiscal, diz o relatório, "tornou-se táo amplo que os controles administrativos sobre ele se tornaram frágeis, requerendo mudanças legais e administrativas urgentes" ${ }^{51}$. O relatório considera que houve a adoção de medidas nesse sentido, como a Instrução Normativa no 1/2017, e defende um aprimoramento da norma instituída, com melhorias na fiscalização e na transparência.

47 BENHAMOU, Françoise. A economia da cultura. Cotia, SP: Ateliê Editorial, 2007. p. 54.

48 REIS, Ana Carla Fonseca: Marketing Cultural e financiamento da Cultura: teoria e prática em um estudo internacional comparado. São Paulo: Pioneira Thomson Learning, 2003. p. 267.

49 REIS, Ana Carla Fonseca: Marketing Cultural e financiamento da Cultura: teoria e prática em um estudo internacional comparado. Sáo Paulo: Pioneira Thomson Learning, 2003. p. 287.

50 BRASIL. Câmara dos Deputados. CPI - Lei Rouanet: relatório final. Brasília, 2017. Disponível em: http://www2.camara.leg.br/ camaranoticias/noticias/EDUCACAO-E-CULTURA/531663-RELATORIO-FINAL-DA-CPI-DA-LEI-ROUANET-SUGEREINDICIAMENTO-DE-INVESTIGADOS.html. Acesso em: 8 nov. 2018. p. 340.

51 BRASIL. Câmara dos Deputados. CPI - Lei Rouanet: relatório final. Brasília, 2017. Disponível em: http://www2.camara.leg.br/ camaranoticias/noticias/EDUCACAO-E-CULTURA/531663-RELATORIO-FINAL-DA-CPI-DA-LEI-ROUANET-SUGEREINDICIAMENTO-DE-INVESTIGADOS.html. Acesso em: 8 nov. 2018. p. 340. 
Os critérios para aprovação de projetos constam no dispositivo 22 da Lei no 8.313/91 e dizem o seguinte: "Os projetos enquadrados nos objetivos desta lei não poderão ser objeto de apreciação subjetiva quanto ao seu valor artístico ou cultural." 52 As decisôes sobre a aprovação desses projetos, além de não permitirem a avaliação subjetiva da arte, entrega tal decisão a um corpo colegiado que envolve o próprio Ministério da Cultura e a Comissão Nacional de Incentivo à Cultura (CNIC).

Para Cunha Filho53: "A Comissão Nacional de Incentivo à Cultura (CNIC) nasce de um imperativo constitucional, e náo de mera liberalidade do legislador ordinário". Mas tais diretrizes não impediram decisóes questionáveis envolvendo a captação de recursos via Rouanet sob aspectos distintos, seja pela temática, seja pelo valor autorizado de captação.

A discussão recai sobre o que deveria ser cultura/arte, e vai mais além do que deveria ser projeto cultural, sob o prisma do financiamento público. O relatório da CPI da Lei Rouanet trata a questão da seguinte forma:

Quase toda produção humana pode ser caracterizada como cultural, mas, convencionalmente, necessita-se de mínima sistematização e institucionalização - ainda que informal - de produtos culturais para que as práticas culturais possam ser objeto de incentivo e apoio, seja ele público ou privado. Como não há recursos (não somente financeiros) infinitos à disposição de qualquer setor, inclusive o da cultura, as instituiçóes que patrocinam a cultura são obrigadas a selecionar as manifestaçóes culturais que apoiarão. ${ }^{54}$

Cesnik $^{55}$ pontua que a Lei Rouanet atenta para essa definição básica existente na Constituição. Segundo ele, as áreas que merecem atenção da lei devem necessariamente envolver: desenvolvimento de formas de expressão cultural, os modos de criar e fazer, a preservação e a proteção do patrimônio cultural brasileiro, além de estudos que estimulem a intepretação cultural.

Observa-se, sob o prisma legislativo, que as concepçóes em torno da subjetividade da arte estáo delimitadas, inicialmente pela Constituição, e pela própria lei. A aprovação de projetos via mecenato segue um extenso caminho que afunila as demandas justamente em razão de tratar-se de financiamento público, por meio de incentivo fiscal.

52 BRASIL. Lei no 8.313, de 23 de dezembro de 1991. Restabelece princípios da Lei n 7.505, de 2 de julho de 1986, institui o Programa Nacional de Apoio à Cultura (Pronac) e dá outras providências. Presidência da República, Brasília, DF, 1991. Disponível em: http://www.planalto.gov.br/ccivil_03/LEIS/L8313cons.htm. Acesso em: 7 nov. 2018.

53 CUNHA FILHO, Francisco Humberto. Cultura e democracia na Constituiçāo Federal de 1988: representação de interesses e sua aplicação ao Programa Nacional de Apoio à Cultura. 2004. 234 f. Tese (Doutorado em Direito) - Faculdade de Direito do Recife, Universidade Federal de Pernambuco, Recife, 2004. Disponível em: http://www.direitosculturais.com. br/artigos_interna. php?id=116. Acesso em: 25 out. 2017. p. 171.

54 BRASIL. Câmara dos Deputados. CPI - Lei Rouanet: relatório final. Brasília, 2017. Disponível em: http://www2.camara.leg.br/ camaranoticias/noticias/EDUCACAO-E-CULTURA/531663-RELATORIO-FINAL-DA-CPI-DA-LEI-ROUANET-SUGEREINDICIAMENTO-DE-INVESTIGADOS.html. Acesso em: 8 nov. 2018. p. 19-20.

55 CESNIK, Fábio de Sá. Guia do incentivo à cultura. 2. ed. Barueri: Manole, 2007. p. 36. 
Para Pompeu e Siqueira, essa delimitação clara deveria se traduzir em transparência para a efetivação de políticas públicas e quanto mais transparentes as iniciativas do Estado forem, mais fortes serão suas instituições, o que favorece, na visão das mesmas, a realização "de direitos sociais, de garantir direitos adquiridos e segurança jurídica de representar a população" 56 .

De forma complementar, Cunha Filho ${ }^{57}$ demonstra essa valoração das instituições, no aspecto dos direitos culturais, ao afirmar que o apoio estatal por meio do fomento deverá ser ofertado com base nos fundamentos da soberania, da cidadania, dos valores sociais do trabalho e da livre iniciativa, do pluralismo político e da dignidade da pessoa humana (Art. $\left.1^{\circ} \mathrm{da} C F\right) .^{58}$

No entanto, ao avalizar determinados projetos culturais, são grandes os questionamentos sobre estes atenderem às premissas constitucionais já citadas. Tais decisóes que aparentam não estarem em conformidade com os dispositivos da Rouanet surgem justamente em razão de que mesmo com a norma posta, ela não seria uma norma completa, onde se possa aplicar linearmente para todos os casos concretos. Faz-se necessário avaliar cada caso ou cada projeto aprovado sem generalizaçóes. Hans Kelsen previa essa possibilidade do ato jurídico-normativo:

$\mathrm{O}$ ato jurídico que efetiva ou executa a norma pode ser conformado por maneira a corresponder a uma ou outra das várias significaçôes verbais da mesma norma, por maneira a corresponder à vontade do legislador - a determinar por qualquer forma que seja - ou, entáo, à expressão por ele escolhida, por forma a corresponder a uma ou a outra das duas normas que se contradizem ou por forma a decidir como se as duas normas em contradição se anulassem mutuamente. O Direito a aplicar forma, em todas estas hipóteses, uma moldura dentro da qual existem várias possibilidades de aplicação, pelo que é conforme ao Direito todo ato que se mantenha dentro deste quadro ou moldura, que preencha esta moldura em qualquer sentido possível. ${ }^{59}$

Portanto, faz-se necessário entender o projeto, a fim de enumerar onde o mesmo se enquadra nas premissas previamente estabelecidas na norma constitucional e ordinária. A subjetividade artística é permitida, desde que tal liberdade de criar não atinja princípios constitucionais como a dignidade humana, o pluralismo político, os valores sociais, entre outros.

Ocorre que mesmo com a possibilidade de liberdade artística, certos projetos são preteridos em razão de outros semelhantes. Nesse caso, embora a lei traga o alinhamento

56 POMPEU, Gina Vidal Marcílio; SIQUEIRA, Natercia Sampaio. Democracia Contemporânea e os critérios de justiça para o desenvolvimento socioeconômico: Direito Constitucional nas relaçôes econômicas. Rio de Janeiro: Lumen Juris, 2017. p. 169.

57 CUNHA FILHO, Francisco Humberto. Cultura e democracia na Constituição Federal de 1988: representação de interesses e sua aplicação ao Programa Nacional de Apoio à Cultura. 2004. 234 f. Tese (Doutorado em Direito) - Faculdade de Direito do Recife, Universidade Federal de Pernambuco, Recife, 2004. Disponível em: http://www.direitosculturais.com.br/artigos_interna. php?id=116. Acesso em: 25 out. 2017. p. 47-48.

58 BRASIL. Constituição da República Federativa do Brasil de 1988. Presidência da República, Brasília, DF, 1988. Disponível em: http://www.planalto.gov.br/ccivil_03/constituicao/constituicao.htm. Acesso em: 7 nov. 2018.

59 KELSEN, Hans. Teoria pura do direito. 6. ed. Sáo Paulo: Martins Fontes, 1998. p. 247. 
que os projetos devem seguir, é possível que o aplicador da norma esteja se atendo a uma decisão política sobre o projeto e não jurídico-normativa, de forma a estimular um desvio de finalidade da legislação vigente, já sinalizado no relatório da CPI sobre o tema.

Reitere-se que projetos culturais não podem ser rejeitados unicamente baseados em avaliação de mérito. Faz-se necessário averiguar a clareza, a precisão e o atendimento aos preceitos legais e normativos, bem como a conformidade e a adequação em relação aos objetivos declarados pelo proponente. Fukuyama ${ }^{60}$ expóe de forma muito clara que decisóes que ultrapassam o ato jurídico-normativo somente servem para enfraquecer o papel que as instituiçóes possuem para a efetivação de políticas públicas e que estaria nas decisóes políticas do aplicador a resposta para a dificuldade que diversos governos no mundo possuem em garantir serviços públicos, de cumprirem a lei e, por conseguinte, fazer valer o interesse público.

É necessário que o caráter de subjetividade inerente ao contexto da Lei Rouanet aqui tratado deva sempre se referir à atuação do aplicador da norma, com a utilização dos limites (moldura) definidos pelos princípios constitucionais já citados, de modo a associar estes às regras expostas de forma clara nos artigos 18 e 26 da norma em questáo.

O aplicador, caso exceda tais limites, já não estaria a navegar no aspecto do direito positivo, conforme bem delimita Hans Kelsen ${ }^{61}$ : "Na medida em que, na aplicação da lei, para além da necessária fixação da moldura dentro da qual se tem de manter o ato a pôr, possa ter ainda lugar uma atividade cognoscitiva do órgão aplicador do Direito, não se tratará de um conhecimento do Direito positivo, mas de outras normas [...]", afirma.

Observa-se que ao analisar os pontos importantes e polêmicos sobre a Lei Rouanet, tem-se a compreensão de que a lei ordinária é muito maior do que os aspectos negativos que a cercam, embora esses aspectos não sejam menos importantes, uma vez que se trata de gestão e dinheiro público.

O fomento destinado na Lei merece ainda outros debates, além dos pontos citados, como a inserção de projetos de grande alcance comercial como candidatos à renúncia fiscal, por exemplo. No caso específico, a Lei não faz distinção de projetos, o que, de certa forma, atende formalmente a uma premissa democrática. No entanto, materialmente se traduz em concentraçáo de projetos atrelados a grandes nomes do meio artístico-cultural e em regióes com mercados consumidores maduros.

Para Menezes ${ }^{62}$, o debate náo deve adentrar nesse viés preconceituoso. $\mathrm{O}$ pesquisador defende, por exemplo, que a Lei não pode adotar tratamentos distintos em razão de ser um artista famoso ou não. Essa posição deve ser defendida, sobretudo, na modalidade do mecenato, que é a linha de fomento existente justamente para projetos de

60 FUKUYAMA, Francis. Ordem política e Decadência política: da revoluçâo industrial à globalização da Democracia. Alfragide, Portugal: Dom Quixote, 2015. p. 116.

61 KELSEN, Hans. Teoria pura do direito. 6. ed. São Paulo: Martins Fontes, 1998. p. 249.

62 MENEZES, Henilton. A Lei Rouanet: muito além dos (F)atos. São Paulo: E-galaxia, 2016. p. 108. 
grande visibilidade. É necessário respeitar a posição da iniciativa privada no sentido de escolher onde quer investir.

Essa necessidade, segundo Reis ${ }^{63}$, decorre do entendimento de que não há altruísmo gratuito no setor privado. A responsabilidade social das empresas não tem base apenas na ética ou no bem-estar, mas também no lucro gerado pela exposição de seu nome vinculado a determinadas iniciativas, exatamente como se propóe o mecenato da Lei Rouanet. Com isso, entende-se que se faz necessário produzir por meio de atualizaçóes dessas linhas de fomento, a inclusão de mecanismos que estimulem o mercado a investir em projetos considerados menos atraentes e náo criar empecilhos para o investidor (limitando sua liberdade de escolha) atuar na área da Cultura, através do incentivo indireto.

\section{Conclusão}

Verifica-se que no Século XXI, a Lei Rouanet ganhou bastante atenção por parte da mídia e da sociedade de uma forma geral, não pelo que ela se propóe na sua essência formal, e sim no que ela se tornou materialmente, basicamente em razão da má gestão e do desvirtuamento do que foi a vontade do legislador. Entretanto, o que se observa é que os debates que envolvem o fomento à cultura, por meio desta norma, são rasos e fazem uso de senso comum distorcido e porque não dizer manipulado.

Mas o debate sobre o tema se faz necessário, a cultura merece sua inserção como política pública prioritária, pois ela claramente contribui positivamente para a formação de uma sociedade com senso moral maduro e racional. Além disso, quando bem posta, a cultura pode se tornar um vetor de divisas para o Estado e para a iniciativa privada, ao se considerar que a cultura não seria uma área de investimento a fundo perdido, o seu retorno mercantilista também é possível.

O Estado de bem-estar social, almejado e necessário para as diversas naçóes do globo, só será efetivado plenamente se a cultura tiver sua atenção devida, bem como os demais direitos, sejam eles econômicos ou sociais, cuja finalidade será de obter desenvolvimento humano amplo e sólido. Tais direitos são frutos, inclusive, de pactos internacionais firmados pelo Brasil, dentre os quais o maior deles, no caso a Declaração Universal dos Direitos Humanos, que completou 70 anos, em 2018.

Esse comprometimento do país influenciará o texto constitucional brasileiro que garante pleno acesso aos chamados direitos culturais. A Lei no 8.313/91 é peça dessa grande engrenagem a qual o país se comprometeu a cumprir perante a comunidade internacional, sem possibilidade de retrocesso.

63 REIS, Ana Carla Fonseca: Marketing Cultural e financiamento da Cultura: teoria e prática em um estudo internacional comparado. São Paulo: Pioneira Thomson Learning, 2003. p. 21-22. 
Ocorre que a norma, seja ela qual for, tem dois lados ou perspectivas, quais sejam: o que deve ser feito e o que realmente é feito. Essa dicotomia entre o ser e o dever ser impede o pleno exercício dos ditames existentes na lei. Há, por parte do Estado, manipulação e ausência de vontade com a área cultural, e isso ocorre por diversos motivos: distintas prioridades, desconhecimento das possibilidades econômicas e manipulação política das ferramentas de fomento existentes. No entanto, a norma segue seu caminho de fomentar a cultura no país e os números mostram isso.

A Lei Rouanet, com limitaçóes e carências, continua sendo a mais importante lei do gênero no país, que necessita da iniciativa estatal para direcionar o desenvolvimento desta área estratégica. Fala-se bastante da revogação de tais linhas de fomento, muito em razão do mecenato que prevê a renúncia fiscal como incentivador. Entretanto, os números oficiais revelam que tais incentivos não atingiram $1 \%$ de todas as desoneraçóes previstas pelo Estado no ano de 2017.

Indaga-se, então, que tipo de economia se teria com essa medida? Ressalte-se ainda que tal revogaçáo poderia representar, perante a comunidade internacional, um retrocesso, com penalidades previstas no âmbito das Naçóes Unidas. Não menos importante está o protocolo adicional de 2008 do PIDESC náo ratificado pelo Brasil, que, entre outras ferramentas, permite ao cidadáo cobrar judicialmente a execuçáo de tais direitos, cuja responsabilidade é do Estado. O país, diante da comunidade internacional e dos brasileiros, precisa assumir essa iniciativa, o que torna essencial a ratificaçáo do protocolo adicional.

Em consonância com essa iniciativa está o relatório produzido em 2017 pela CPI da Lei Rouanet, que mostra os caminhos que devem ser seguidos e afirma que a Lei deve ser aprimorada e não revogada. Além disso, o próprio relatório revela que já existem iniciativas governamentais para impedir desvios de finalidade com as verbas envolvendo a Rouanet.

Entretanto, é necessário fazer com que a Lei atenda, de fato, a todo o país. A própria norma prevê essa amplitude com as linhas distintas de fomento, mas na prática apenas uma, o mecenato - dirigido a grandes espetáculos - funciona. Destarte, é essencial a aplicaçáo da norma conforme o legislador determinou e a discussáo de mecanismos que possam ser incorporados à lei que permitam a distribuição do fomento a todas as regiōes. Ressalta-se a carência da aplicação efetiva de políticas de fiscalização, por meio da utilização da própria estrutura estatal. Afinal, conciliar crescimento econômico com desenvolvimento cultural requer planejamento, incentivo e fiscalização.

\section{Referências}

BENHAMOU, Françoise. A economia da cultura. Cotia, SP: Ateliê Editorial, 2007. 
BERCOVICI, Gilberto. Política econômica e direito econômico. Pensar, Fortaleza, v. 12, n. 2, p. 363-836, jun. 2011. Disponível em: http://periodicos.unifor.br/rpen. Acesso em: 7 nov. 2018.

BRASIL. Lei no 7.505, de 2 de julho de 1986. Dispóe sobre benefícios fiscais na área do imposto de renda concedidos a operaçóes de caráter cultural ou artístico. Presidência da República, Brasília, DF, 1986. Disponível em: http://www.planalto.gov.br/ccivil_03/ LEIS/L7505.htm. Acesso em: 8 nov. 2018.

BRASIL. Constituição da República Federativa do Brasil de 1988. Presidência da República, Brasília, DF, 1988. Disponível em: http:/www.planalto.gov.br/ccivil_03/ constituicao/constituicao.htm. Acesso em: 7 nov. 2018.

BRASIL. Lei no 8.313, de 23 de dezembro de 1991. Restabelece princípios da Lei $\mathrm{n}^{\circ} 7.505$, de 2 de julho de 1986, institui o Programa Nacional de Apoio à Cultura (Pronac) e dá outras providências. Presidência da República, Brasília, DF, 1991. Disponível em: http://www.planalto.gov.br/ccivil_03/LEIS/L8313cons.htm. Acesso em: 7 nov. 2018.

BRASIL. Protocolo facultativo ao PIDESC: uma ferramenta para exigir os DESC. 2009. Disponível em: pfdc.pgr.mpf.mp.br/atuacao-e-conteudos-de-apoio/publicacoes/ direitos-humanos/protocolo. Acesso em: 8 nov. 2018.

BRASIL. Câmara dos Deputados. CPI - Lei Rouanet: relatório final. Brasília, 2017. Disponível em: http://www2.camara.leg.br/camaranoticias/noticias/EDUCACAO-ECULTURA/531663-RELATORIO-FINAL-DA-CPI-DA-LEI-ROUANET-SUGEREINDICIAMENTO-DE-INVESTIGADOS.html. Acesso em: 8 nov. 2018.

BRASIL. FNC. Disponível em: http://rouanet.cultura.gov.br/fnc/. Acesso em: 6 nov. 2018a.

BRASIL. Ministério da Cultura. Sistema de Apoio às Leis de Incentivo à Cultura. Salic. Disponível em: http://sistemas.cultura.gov.br/comparar/salicnet/salicnet.php\#. Acesso em: 6 nov. 2018 b.

BRASIL. Receita Federal do Brasil. Demonstrativo dos Gastos Governamentais Indiretos de Natureza Tributária. Brasilia: Receita Federal, 2018c. Disponível em: http://idg. receita.fazenda.gov.br/dados/receitadata/renuncia-fiscal/previsoes-ploa/arquivos-eimagens/demonstrativos-dos-gastos-tributarios-dgt. Acesso em: 5 nov. 2018.

CESNIK, Fábio de Sá. Guia do incentivo à cultura. 2. ed. Barueri: Manole, 2007. COMISSÃO INTERAMERICANA DE DIREITOS HUMANOS. Convenção Americana sobre Direitos Humanos. San José, Costa Rica, em 22 de novembro de 1969. Disponível em: https://www.cidh.oas.org/basicos/portugues/c.convencao_americana. htm. Acesso em: 8 nov. 2018. 
COSTA, Maíra Lopes Viana da. A lei de incentivo como politica cultural: o papel da comissão nacional de incentivo à cultura. 2013. 116 f. Dissertação (Mestrado em Bens Culturais e Projetos Sociais) - Fundação Getúlio Vargas, Rio de Janeiro, 2013. Disponível em: https://bibliotecadigital.fgv.br/dspace/bitstream/handle/10438/11293/ Dissertação-Maíra LopesViana da Costa.pdf. Acesso em: 1 dez. 2017.

COSTA, Rodrigo Viera; TELLES, Mário Ferreira de Pragmácio. Cultura e Direitos culturais. Rio de Janeiro: Lumen Juris, 2017.

CUNHA FILHO, Francisco Humberto. Cultura e democracia na Constituição Federal de 1988: representação de interesses e sua aplicação ao Programa Nacional de Apoio à Cultura. 2004. 234 f. Tese (Doutorado em Direito) - Faculdade de Direito do Recife, Universidade Federal de Pernambuco, Recife, 2004. Disponível em: http://www. direitosculturais.com.br/artigos_interna.php?id=116. Acesso em: 25 out. 2017.

CUNHA FILHO, Francisco Humberto. A mutação do Locus Jurídico do Tombamento: do direito administrativo para os direitos culturais. Publicaçóes Escola da Agu, Brasília, v. 9, n. 3, p. 100-117, jan. 2017. Disponível em: http://seer.agu.gov.br/ index.php/EAGU/issue/view/124. Acesso em: 5 nov. 2018.

FUKUYAMA, Francis. Construção de Estados. Rio de Janeiro: Rocco, 2005.

FUKUYAMA, Francis. Ordem política e Decadência politica: da revolução industrial à globalização da Democracia. Alfragide, Portugal: Dom Quixote, 2015.

GOMES, Ana Paula de Oliveira. A problemática dos fundos de investimento cultural e artístico (FICART). In: ENCONTRO INTERNACIONAL DE DIREITOS CULTURAIS, 2., 2013, Fortaleza. Anais [...]. Fortaleza: OUI-IOHE, 2013. Disponível em: www.direitosculturais.com.br/download.php?id=59. Acesso em: 8 nov. 2018.

HESSE, Konrad. A força normativa da Constituição. Porto Alegre: Sergio Antonio Fabris Editor, 1991.

KELSEN, Hans. Teoria pura do direito. 6. ed. São Paulo: Martins Fontes, 1998.

LASSALE, Ferdinand. A Essência da Constituição. 5. ed. Rio de Janeiro: Lumen Juris, 2000.

LEÃO, Renato Zerbini Ribeiro. O Acesso direto dos indivíduos ao Comitê de Direitos Econômicos, Sociais e Culturais da ONU. Universitas Relaçôes Internacionais, Brasilia, v. 11, n. 1, p. 28-38, jan. 2013. Disponível em: https://www.publicacoesacademicas. uniceub.br/relacoesinternacionais/article/download/2325/2068. Acesso em: 8 nov. 2018.

MENEZES, Henilton. A Lei Rouanet: muito além dos (F)atos. São Paulo: E-galaxia, 2016. 
NUSSBAUM, Martha C. Sem fins lucrativos: Por que a democracia precisa das humanidades: WMF Martins Fontes, 2015.

ORGANIZAÇÃO DAS NAÇÕES UNIDAS. A Declaração Universal dos Direitos Humanos. 1948. Disponível em: https://nacoesunidas.org/direitoshumanos/declaracao/. Acesso em: 8 nov. 2017.

ORGANIZAÇÃO DAS NAÇÓES UNIDAS. 17 objetivos para transformar nosso mundo. 2015. Disponível em: https://nacoesunidas.org/pos2015/ods16/. Acesso em: 8 nov. 2017.

PIOVESAN, Flávia. Direitos Humanos e o Direito Constitucional Internacional. 15. ed. São Paulo: Saraiva, 2015.

POMPEU, Gina Vidal Marcílio; SIQUEIRA, Natercia Sampaio. Democracia Contemporânea e os critérios de justiça para o desenvolvimento socioeconômico: Direito Constitucional nas relações econômicas. Rio de Janeiro: Lumen Juris, 2017.

POMPEU, Gina Vidal Marcílio; FIGUEIREDO NETO, Manoel Valente. Artigo $6^{\circ}$. In: BALERA, Wagner; SILVEIRA, Vladmir Oliveira da; COUTO, Mônica Bonetii. Comentários ao Pacto Internacional dos Direito Econômicos, Sociais e Culturais. Curitiba: Clássica, 2013. p. 111-127.

REIS, Ana Carla Fonseca: Marketing Cultural e financiamento da Cultura: teoria e prática em um estudo internacional comparado. Sáo Paulo: Pioneira Thomson Learning, 2003.

ROJAS, Lucero Ibarra. Políticas Culturales y Derechos Culturales através de los Diablos de Ocumicho. Direito, Estado e Sociedade, Rio de Janeiro, n. 48, p. 196-223, jan. 2016.

SANTOS, Fernando Burgos Pimentel dos. Política Cultural no Brasil: histórico de retrocessos e avanços institucionais. In: ENCONTRO DA ANPAD, 33., 2009, São Paulo. Anais [...]. São Paulo: Anpad, 2009. Disponível em: http://www.anpad.org.br/ admin/pdf/APS3105.pdf . Acesso em: 2 nov. 2018.

SEN, Amartya. A ideia de justiça. Rio de Janeiro: Companhia Digital, 2011.

UNITED NATIONS HUMAN RIGHTS. Informe del Alto Comisionado de las Naciones Unidas para los Derechos Humanos. 2006. Disponível em: https://www.ohchr. org/SP/Pages/Home.aspx. Acesso em: 8 nov. 2018

UNITED NATIONS HUMAN RIGHTS. Ratificação do Pacto Internacional sobre Direitos Econômicos, Sociais e Culturais, janeiro 2013. 2013. Disponível em: https:// www.ohchr.org/en/professionalinterest/pages/cescr.aspx. Acesso em: 2 nov. 2018. 